\title{
Body Mass Index, Age, Sexual Maturation and Incidence of Hyperlordosis in Children and Adolescents
}

\author{
Índice de Massa Corporal, Idade, Maturação Sexual e a Incidência de \\ Hiperlordose Lombar em crianças e adolescentes
}

\author{
Cristianne Morgado Montenegro (iD [a], Tatiana Affornali Tozo (iD) ${ }^{[a]}$, Beatriz Oliveira Pereira (iD [a], \\ João Otacílio Libardoni dos Santos [i] [b]*
}

[a] Universidade do Minho (UM), Braga, Portugal

[b] Universidade Federal do Amazonas, Manaus, AM, Brazil

\begin{abstract}
Introduction: Hyperlordosis can cause several degenerative spinal pathologies in children and adolescents. Objective: Determine whether body mass index, age and sexual maturation predict the occurrence of hyperlordosis in children and adolescents. Method: The study analyzed 380 students aged between 10 and 18 years. Body mass index was evaluated using the reference values suggested by the Fitnessgram test battery, and sexual maturation through Tanner's scale of self-assessed pubic hair growth. Postural assessment was conducted using the DIPA photogrammetry method, version 3.1. (Digital Image Based Postural Assessment) The SPSS 24.0 program was used to analyze the data, and the following statistical tests were applied: chi-squared, Mann-Whitney, Fisher's exact and binary logistic regression. Results: There was statistical significance between hyperlordosis, girls' age and puberty in boys $(\mathrm{p}<0.05)$. The adjusted binary logistic regression for the girls $(\mathrm{OR}=0.656)$ indicated that this disorder declined by $34 \%$ with advancing age and for stage P2 of puberty in boys ( $\mathrm{OR}=4.292)$, and the likelihood of boys' presenting with hyperlordosis
\end{abstract}

*CMM: Doctoral student, email: cristianne.morgado@gmail.com

TAT: Doctoral student, email: tatinali@yahoo.com.br

BOP: PhD, email: beatriz@ie.uminho.pt

JOLS: PhD, email: jlibardoni@yahoo.com.br 
at this stage is approximately 4-fold higher. There was no statistical significance between body mass index and hyperlordosis ( $\mathrm{p}>0.05)$. Conclusion: The girls' age and boys' stage of puberty were associated with the occurrence of hyperlordosis.

Keywords: Lordosis. Puberty. BMI. Children. Adolescents.

\section{Resumo}

Introdução: A Hiperlordose lombar pode ocasionar diversas patologias degenerativas na coluna vertebral de crianças e adolescentes. Objetivo: Identificar se o Índice de Massa Corporal, a Idade e a Maturação Sexual são previsores da ocorrência da hiperlordose lombar em crianças e adolescentes. Método: O estudo analisou 380 estudantes entre 10 e 18 anos. O Índice de Massa Corporal foi avaliado por meio dos valores de referência sugeridos pela bateria de testes Fitnessgram e a maturação sexual por meio da auto-avaliação da pilosidade pubiana de Tanner. A avaliação postural foi realizada pelo método de fotogrametria DIPA versão 3.1. (Avaliação Postural Baseada em Imagem Digital). Para análise dos dados foi utilizado o programa SPSS 24.0, tendo sido aplicados os testes estatísticos: Qui-Quadrado, Mann Whitney, Exato de Fisher e Regressão Logística Binária. Resultados: Observou-se que houve significância estatística entre a Hiperlordose lombar e a idade das meninas e a puberdade dos meninos $(p<0,05)$. A regressão logística binária ajustada para o grupo das meninas $(0 R=0,656)$ apresentou a posssibilidade de que com o avanço da idade esta patologia diminui sua ocorrência em 34\% e no grupo dos meninos (OR=4,292), a puberdade foi significativa na fase P2, verificando-se que a chance dos meninos apresentarem a hiperlordose lombar nesta fase é aproximadamente 04 vezes maior. Não houve significância estatística entre o Índice de Massa Corporal, a Idade e a Maturação Sexual e a hiperlordose lombar ( $>>0,05)$. Conclusão: A idade das meninas e a puberdade dos meninos foi associada à ocorrência da hiperlordose lombar.

Palavras-chave: Lordose. Puberdade. IMC. Crianças. Adolescentes.

\section{Introduction}

The large number of postural changes and dysfunctions among children and adolescents [1] is a concerning social problem [2]. Postural changes in the curvature of the lumbar region may lead to severe pathological dysfunctions [3]. According to Berven et al., changes in spinal alignment have a significant influence on range of motion and can cause serious disturbances to the intervertebral disks and several degenerative diseases, interfering negatively in the health-related quality of life of children and adolescents [4].

Lumbar lordosis (hyperlodosis) acts significantly against gravity, supporting a large part of body weight when compared to the thoracic and sacral spine, where peak development occurs during puberty [5], between the ages of 8 and 13 years in girls and 10 and 15 in boys [6]. Data show that motor failure in the lumbar region and body mass index are considered risk factors for nonspecific pain in this region in children and adolescents $[7,8]$, and an increase in lumbar lordosis angle is related to both age [9] and excess body weight [10].

In a systematic review, Kasten et al. [11] reported that although Brazil stands out for the number of studies on body posture, there is still no consensus in the literature that attributes a single risk factor for postural changes, suggesting its cause is multifactorial [12]. In this respect, the present study aims at determining whether BMI, age and sexual maturation are predictors of hyperlordosis in children and adolescents. 
Methods

\section{Sample and study type}

This is a cross-sectional, analytical, descriptive study of a convenience sample of 380 students, $54 \%(n=204)$ girls and 46\% ( $\mathrm{n}=176)$ boys, aged between 10 and 18 years, with an average age of $12.6 \pm 1.68$ years for girls and $13.03 \pm 1.76$ years for boys. All the participants were enrolled in the 5 th to 9 th grades at two municipal schools in Manaus, Amazonas state, Brazil. The study was approved by the Research Ethics Committee of the Estácio Faculty of Amazonas, under protocol CAAE no. 73683517.9.0000.5017, and in line with the ethical principles contained in the 1995 Declaration of Helsinki.

In order to take part in the study, parents or guardians provided written informed consent and the students signed a term of agreement. Exclusion criteria were students diagnosed with neurological or rheumatological disease or any other disorder that affected body posture and the locomotor apparatus, those who were frequently absent from classes and who refused to undergo any of the tests during the study.

\section{Data collection instruments}

Body composition was determined by BMI, calculated by the ratio between body weight in kilograms and height in meters squared [BMI = weight $(\mathrm{kg}) /$ height2 (m)] [13]. Weight was measured on a Filizola anthropometric balance with a maximum capacity of $150 \mathrm{Kg}$ and accurate to 100 grams. Height was measured using a stadiometer graduated in millimeters and measured in centimeters. To measure weight and height, the boys wore shorts, but remained barefoot and shirtless. The girls wore shorts and a mini blouse and were barefoot. BMI was classified based on the Fitnessgram values [14], where healthy status was at least $16.6 \mathrm{Kg} / \mathrm{m}^{2}$ at ten years of age for girls and a maximum of $27.3 \mathrm{Kg} / \mathrm{m}^{2}$ at the age of 18 . The minimum classification used for boys was $15.3 \mathrm{Kg} / \mathrm{m}^{2}$ at the age of ten and a maximum of $27.8 \mathrm{Kg} / \mathrm{m}^{2}$ at 18 . The BMI classification used showed that children within the healthy zone exhibited adequate weight for their age group and the children and adolescents in the unhealthy group who were above the recommended values were overweight for their age and those below the minimum underweight [14].
In order to determine sexual maturation, Tanner's self-assessed pubic hair growth scale, illustrated via diagrammatic presentation, is classified into five sexual maturation stages. Stage 1 is considered pre-pubertal; stages 2, 3 and 4 pubertal and stage 5 post-pubertal. Students marked an $\mathrm{X}$ beside the figure that most closely represented their own stage, which was subsequently classified by the researcher [15].

In order to determine the angular values of lumbar lordosis, the Digital Image-based Postural Assessment (DIPA) photogrammetric method, version 3.1, was used. This simple instrument is a largely noninvasive, lowcost, valid and practical technique to analyze the spine in the sagittal and frontal planes and provide other potential information to researchers [16].

\section{Data collection procedures}

Physical and postural assessments were carried out in a private room prepared specifically for this study. The students were monitored individually up to data collection, which initially involved filling out the student identification chart with the following information: age, sex, birthdate, parents' or guardians' schooling level, and school grade, data the researcher subsequently confirmed with the school administration.

After this stage, students received the self-assessment pubic hair growth chart proposed by Tanner [15], marking the figure most appropriate for their respective stage. In the next stage, height and weight were measured to calculate BMI, with students standing barefoot on the anthropometric balance, arms extended along their body and chin parallel to the floor.

In the following stage, posture was analyzed using the Digital Image-based Postural Assessment (DIPA) photogrammetric method, version 3.1. Based on the angular values, the students were classified according to the criteria proposed by the program: physiological lumbar lordosis angle from 31 to $49.5^{\circ}$ and $>49.5^{\circ}$ [16].

First, a black cloth $(2.00 \times 2.00 \mathrm{~m})$ was mounted at the end of the evaluation room. During this procedure, students were asked to assume the orthostatic position,

in the posterior plane, with arms relaxed at their sides and chin parallel to the floor, after which anatomic points were marked with a Mitsubishi 7600 dermatograph pencil (black micropigmentation). Next, the following stages were conducted: (1) palpation and marking of specific DIPA protocol reference points, consisting 
of 6 small white markers (Styrofoam balls) with a diameter of $1 \mathrm{~cm}$, attached to the following anatomical points: $\mathrm{CO}, \mathrm{C} 1, \mathrm{C} 2, \mathrm{C} 4, \mathrm{C} 6$ and $\mathrm{C} 7$ and 10 rod-shaped markers, each consisting of a plastic base and small white ball, whose total length is $4.5 \mathrm{~cm}$, to be attached to the anatomical points; placing the Canon Power Shot SX500 IS digital camera (16 megapixels, $35 \mathrm{~mm}$ lens) on a tripod $2.8 \mathrm{~m}$ from the subject and $0.95 \mathrm{~m}$ from the floor. Two photos were taken of the body posture of each student, in the right sagittal plane, with their hands crossed in front of their body; (3) a plumb line with two medium white markers $1.00 \mathrm{~m}$ apart was suspended from the ceiling $1.05 \mathrm{~m}$ away from the back wall, to coincide with the same depth as the lateral malleolus of the student's right heel; (4) photographic record, followed by observation and computer analysis of the photos; (5) digitizing the photos in the software; and (6) producing the DIPA postural report by transferring the photographs to a Samsung NP300E5K computer [16].

After the physical and postural assessments, the students returned to their classroom accompanied by the researcher.

\section{Statistical Analysis}

The data were presented as mean, standard deviation, frequency and percentage. The Mann-Whitney test was used for intergroup comparison and the chisquared and Fisher's Exact tests to analyze the association between variables. The last test was used when the expected frequency was not met. The binary logistic regression model was applied to determine whether age (for girls) and puberty (for boys) are predictors of hyperlordosis. The significance level was set at $p \leq$ 0.05 . The data were analyzed in IBM SPSS Statistics 24 .

\section{Results}

The association between hyperlordosis and BMI showed no significant differences for girls $(p=0.380)$ or boys $(\mathrm{p}=0.987$ ) (Table 1$)$.
Table 1 - Incidence of hyperlordosis using body mass index according to the Fitnessgram protocol, for girls and boys

\begin{tabular}{|c|c|c|c|c|c|c|c|}
\hline BMI & \multicolumn{4}{|c|}{ Hyperlordosis } & \multicolumn{2}{|c|}{ Total } & p-value \\
\hline Girls & & No & & Yes & & & \\
\hline Unhealthy & 64 & $(93 \%)$ & 5 & $(7 \%)$ & 69 & $(100 \%)$ & $0.380 \mathrm{NS}$ \\
\hline Healthy & 128 & $(95 \%)$ & 7 & $(5 \%)$ & 135 & $(100 \%)$ & \\
\hline Total & 192 & (94\%) & & (6\%) & 204 & (100\%) & \\
\hline Boys & & No & & Yes & & & \\
\hline Unhealthy & 54 & $(92 \%)$ & 5 & $(8 \%)$ & 59 & $(100 \%)$ & $0.987 \mathrm{NS}$ \\
\hline Healthy & 107 & $(92 \%)$ & 10 & $(8 \%)$ & 117 & $(100 \%)$ & \\
\hline Total & 161 & (92\%) & & (8\%) & 176 & (100\%) & \\
\hline
\end{tabular}

Note: NS - Not significant for Fisher's exact test in girls and the chisquared test in boys. BMI - Body mass index.

A comparison of BMI values with respect to the incidence of hyperlordosis and sex (Table 2) also revealed no statistically significant differences in girls $(\mathrm{p}=0.914)$ or boys ( $\mathrm{p}=0.725)$.

Table 2 - Body mass index, according to the incidence of hyperlordosis, for girls and boys

\begin{tabular}{lcccccc}
\hline Hyperlordosis & Mean $\begin{array}{c}\text { Standard } \\
\text { Deviation }\end{array}$ & Median & Minimum Maximum & p-value \\
Girls & & & & & & \\
No & 19.22 & 3.26 & 19.05 & 11.98 & 32.30 & \\
Yes & 19.20 & 3.22 & 18.74 & 15.70 & 27.18 & 0.914 NS \\
Mean & 19.22 & 3.25 & 19.05 & 11.98 & 32.30 & \\
Boys & & & & & & \\
No & 19.57 & 3.84 & 19.14 & 10.22 & 37.81 & \\
Yes & 19.97 & 3.85 & 19.37 & 14.74 & 28.13 & 0.725 NS \\
Mean & 19.61 & 3.84 & 19.20 & 10.22 & 37.81 & \\
\hline
\end{tabular}

Note: NS - Not significant for the Mann-Whitney test. BMI - Body mass index.

A comparison of average age between the individuals with hyperlordosis or not (Table 3 ) showed significant differences in the girls $(\mathrm{p}=0.04)$. However, no statistically significant differences were observed for the boys $(\mathrm{p}=0.195)$. 
Table 3 - Age, according to the incidence of hyperlordosis, by sex

\begin{tabular}{lcccccc}
\hline Hyperlordosis & Mean & $\begin{array}{c}\text { Standard } \\
\text { Deviation }\end{array}$ & Median & Minimum & Maximum & p-value \\
Girls & & & & & & \\
No & 12.7 & 1.67 & 12 & 10 & 17 & \\
Yes & 11.7 & 1.50 & 11 & 10 & 14 & $0.04^{\star *}$ \\
Total & 12.6 & 1.68 & 12 & 10 & 17 & \\
Boys & & & & & & \\
No & 13.1 & 1.74 & 13 & 10 & 17 & $0.195 N S$ \\
Yes & 12.60 & 1.99 & 12 & 10 & 18 & \\
Total & 13.03 & 1.76 & 13 & 10 & 18 & \\
\hline Note: ${ }^{* *} p<0.05$. & NS - Not significant for the Mann-Whitney test.
\end{tabular}

The binary logistic regression model was applied to determine whether age (for girls) is a predictor for the occurrence of hyperlordosis (Table 4). The model containing the age variable was significant for the girls, with an odds ratio (OR) of 0.656 ; that is, for each additional year, the chance of exhibiting hyperlordosis declined by $34 \%$.

Table 4 - Variables included in the logistic regression models, according to sex

\begin{tabular}{lccc}
\hline $\begin{array}{l}\text { Variable } \\
\text { Girls }\end{array}$ & Estimate & $\mathbf{p}$-value & OR \\
Age & -0.421 & 0.049 & 0.656 \\
Boys & & & \\
Puberty (Stage P2) & 1.457 & 0.022 & 4.292 \\
\hline
\end{tabular}

The highest incidence of hyperlordosis in the female subjects occurred among 10-year-olds (17\%), followed by 11 -year-olds ( $9 \%$ ), with lower percentages recorded at ages $13(7 \%), 14(5 \%)$ and 12 years (2\%) and no cases $(0 \%)$ among girls aged 15 to 18 years. Among the boys, the largest incidences were observed at $12(15 \%)$ and 11 years old, followed by 10 -year-olds at $10 \%, 8 \%$ for 16 to 18-year-olds, and 7 and 3\% in 14 and 13-year-old boys, respectively. However, no statistically significant results were recorded between the different age groups and the occurrence of hyperlordosis in boys and girls $(\mathrm{p}<0.05)$.

Table 5 shows that the highest occurrence of hyperlordosis was observed in the pre-puberty stage (P1), with $12 \%$, and the puberty phase (P3), with $8 \%$. In boys, the highest incidence of hyperlordosis was also found in the prepubescent stage (P1), corresponding to $25 \%$ of the students analyzed and in postpubescence (P5), 22\%.
There was a significant association between puberty and the incidence of hyperlordosis (absence and presence of hyperlordosis) in boys ( $\mathrm{p}=0.031$ ) (Table 5 ), but no statistical significance for girls $(\mathrm{p}=0.566)$.

Table 5 - Hyperlordosis by puberty for girls and boys

\begin{tabular}{lcccc}
\hline Puberty & \multicolumn{2}{c}{ Hyperlordosis } & Total & p-value \\
Girls & No & Yes & & \\
P1 & $15(88 \%)$ & $2(12 \%)$ & $17(100 \%)$ & \\
P2 & $52(96 \%)$ & $2(4 \%)$ & $54(100 \%)$ & 0.566 NS \\
P3 & $69(92 \%)$ & $6(8 \%)$ & $75(100 \%)$ & \\
P4 & $50(96 \%)$ & $2(4 \%)$ & $52(100 \%)$ & \\
P5 & $6(100 \%)$ & $0(0 \%)$ & $6(100 \%)$ & \\
Total & $192(94 \%)$ & $\mathbf{1 2 ( 6 \% )}$ & $\mathbf{2 0 4}(\mathbf{1 0 0 \% )}$ & \\
Boys & No & Yes & & \\
P1 & $3(75 \%)$ & $1(25 \%)$ & $4(100 \%)$ & \\
P2 & $48(86 \%)$ & $8(14 \%)$ & $56(100 \%)$ & $0.031^{*}$ \\
P3 & $62(95 \%)$ & $3(5 \%)$ & $65(100 \%)$ & \\
P4 & $41(98 \%)$ & $1(2 \%)$ & $42(100 \%)$ & \\
P5 & $7(78 \%)$ & $2(22 \%)$ & $09(100 \%)$ & \\
Total & $\mathbf{1 6 1}(91.5 \%)$ & $15(8.5 \%)$ & $176(\mathbf{1 0 0} \%)$ & \\
\hline Note. * P<0.05. NS - Not significant for Fisher's exact test.
\end{tabular}

Note: ${ }^{*} p<0.05$. NS - Not significant for Fisher's exact test.

The binary logistic regression model was used to determine whether puberty (for boys) is a predictor of hyperlordosis (Table 4). There was a statistically significant association for stage $\mathrm{P} 2$, with an odds ratio (OR) of 4.292; that is, the chance of exhibiting hyperlordosis in stage P2 is around 4-fold higher than in the other stages (Table 4).

\section{Discussion}

The aim of the present study was to determine whether BMI, age and sexual maturation are predictors of hyperlordosis in children and adolescents. Analysis of the association between hyperlordosis and BMI based on the Fitnessgram protocol, which classifies individuals as healthy or unhealthy, showed that 7\% of unhealthy girls and $5 \%$ of the healthy population exhibited this pathology. In the boys, the results were $8 \%$ for both groups analyzed. However, no significant associations were found between hyperlordosis and BMI for either girls ( $\mathrm{p}=0.380$ ) or boys $(\mathrm{p}=0.987)$. Other studies corroborate our findings, such as those reported by Takayama et al., who obtained statistically significant results between BMI and hyperlordosis in the individuals analyzed here [17]. 
An important aspect to observe in our research was the low incidence of hyperlordosis (7\%) in the students analyzed and the high rate of individuals with BMI in the healthy category that did not exhibit this disorder. These findings suggest that since the percentage of healthy students with no hyperlordosis was significant for both girls and boys ( 95 and $92 \%$, respectively), a large portion of the students analyzed did not develop the condition because they were not overweight. This corroborates Jankowicz-Szymańska etal., who recently found that the pathology was associated with excessive weight gain in children aged between 10 and 12 years [10].

Other studies also reported that normal weight children showed low levels of hyperlordosis, such as that by Kussuki, João and Cunha [18], who found lower indices of the disorder in normal weight children than their obese counterparts (35\% and $62 \%$ respectively). In this respect, Malepe etal. [19] showed that the development of lumbar lordosis may be related to a rise in BMI and in a prospective study, Smith et al. [20] observed that postural misalignment in the sagittal plane may be associated with childhood obesity.

Although the results of the present study were not statistically significant, they suggest that the high number of children and adolescents exhibiting healthy BMI levels (93\% and 92\% in girls and boys, respectively) and no hyperlordosis may be related to the condition's association with high BMI levels [21].

With respect to age, the frequent occurrence of lumbar lordosis in girls aged 10 and 11 years $(10$ and $11 \%$ respectively), and boys ( 11 and $15 \%$ ) at 11 and 12 years of age, respectively. However, the results were not statistically significant ( $p>0.05$ ). Thus, it is important to underscore the study by Rusek et al. [22], who, despite not specifically investigating the occurrence of hyperlordosis at different ages, found considerable postural disorder in the pelvic region of children and adolescents aged between 8 and 16 years.

About the differences between ages and sexes, the highest incidence of hyperlordosis was observed in both girls and boys, at the onset of puberty, between 8 and 13 years of age for girls and between 10 and 15 for boys [6]. However, only in girls were the results statistically significant $(\mathrm{p}<0.05)$, with $34 \%$ likelihood of decreasing with age. Corroborating our results, the prospective study by Mrozkowiak et al. [23] also obtained similar findings, such as a decline in increased hyperlordosis with advancing age in children and adolescents between 4 and 18 years old.
These results may also justify the fact that at the onset of female puberty, the speed of bone maturation over a 2-year period does not accompany their growth spurt and may cause a disproportionate body and muscle hypotonia [24], as reported by Cebeci and Tas [25], who found a lower percentage of muscle mass and lean body mass in the pre-pubertal phase of girls. In addition, at female puberty onset, testosterone secretion is low, not producing enough stimulus to develop muscle mass during this period [26].

With respect to puberty, the highest incidence of lumbar lordosis occurred at the onset and end of male puberty, obtaining statistically significant results. Thus, one of the main characteristics of puberty is the variability between children and adolescents [24], producing significant transformations in body posture. This may be related to the levels of muscle mass [27] and body adiposity [26]. In this respect, it is important to underscore the need to stimulate and develop muscle mass and control fat levels in children and adolescents during the school phase. According to Montoro et al. [28], muscle strength in this population is at undesirable levels, favoring a greater risk of developing noncommunicable chronic diseases.

In the present study, both girls and boys exhibited a higher incidence of hyperlordosis in the initial stages of puberty (prepubescence), obtaining 12 and 25\%, respectively. The results were statistically significant $(\mathrm{p}<0.05)$ between the stages of male puberty and lumbar lordosis. When these results were adjusted by binary logistic regression, that the likelihood of boys' developing lumbar hyperlordosis in stage P2 was approximately 4-fold higher (OR=4.292). These findings may be related to the fact that hormonal changes during puberty affect physical function and body composition [15, 29].

In this respect, in the initial stages of male puberty, at the onset of the pubertal growth spurt, even if stable, muscle strength may decline, causing body imbalance [24], with peak growth rate occurring in the final stage of puberty (P4) [30]. In addition, only 6 months after pubertal growth spurt is the increase in muscle mass stimulated by testosterone secretion [31], influencing strength levels [32] and causing postural deviations.

The results presented indicate that hyperlordosis should be identified during puberty onset in adolescents, using preventive measures such as implementing postural assessment programs to diagnose, treat, and prevent muscle discomforts characteristic of the pathology, making early intervention by health professionals, 
primarily physiotherapists and physical education teachers, essential to prevent hyperlordosis [33].

This study exhibits the following limitations: a cross-sectional design was adopted, making it difficult to establish the cause and effect relationships between the study variables; convenience sampling may have influenced the number of participants in certain analysis strata (low $\%$ of individuals in certain puberty stages as well as healthy and unhealthy subjects) and not controlling the components of body composition, such as the level of muscle mass.

\section{Conclusion}

The aim of the present study was to identify whether BMI, age and sexual maturation are predictors of hyperlordosis in children and adolescents. The results presented here demonstrate that there was no significant association between BMI and hyperlordosis.

When age is related to the disorder, the girls showed $34 \%$ less likelihood of developing hyperlordosis with advancing age. With respect to sexual maturation and hyperlordosis, the data were statistically significant only in stage P2 for boys, and the chance of their exhibiting the disorder at this stage is approximately 4-fold higher.

Given that significant and complex morphological and body transformations are observed at the end of childhood and during adolescence, it is important to encourage postural assessment during the school period, primarily in the 10-12 age range and the onset of puberty.

\section{Acknowledgement}

Funding: This study was funded by CIEC (Center for Investigations in Childhood Studies), Strategic Project UID/CED/00317/2013, via National FCT (Science and Technology Foundation) funds and co-funded by the European Regional Development Fund (FEDER), via COMPETE 2020 - Competitivity and Internalization Operational Program (POCI) under reference number POCI-01-0145-FEDER-007562.

\section{References}

1. Neves MMF, Leite JMRS. Avaliação postural em crianças do ensino fundamental. R Bras Ci Saude. 2016;20(4):285-92.
2. Lubkowska W, Mroczek B. Assessment of body posture of boys aged 7-15 in relation to the body mass indexBMI. J Educ Health Sport. 2017;7(3):371-80.

3. Salem W, Coomans Y, Brismée JM, Klein P, Sobczak S, Dugailly PM. Sagittal thoracic and lumbar spine profiles in upright standing and lying prone positions among healthy subjects: Influence of various biometric features. Spine. 2015;40(15):E900-08.

4. Berven S, Wadhwa R. Sagittal alignment of the lumbar spine. Neurosurg Clin N Am. 2018;29(3):331-9.

5. Fogwe DT, Zulfiqar H, Mesfin FB. Thoracic Discogenic Syndrome. In: StatPearls. Treasure Island, FL: StatPearls Publishing; 2020.

6. Carrascosa A, Yeste D, Moreno-Galdó A, Gussinyé M, Ferrández Á, Clemente $\mathrm{M}$, et al. Pubertal growth of 1,453 healthy children according to age at pubertal growth spurt onset. The Barcelona longitudinal growth study. An Pediatr (Barc). 2018;89(3):144-52.

7. Feng Q, Jiang C, Zhou Y, Huang Y, Zhang M. Relationship between spinal morphology and function and adolescent non-specific back pain: a crosssectional study. J Back Musculoskeletal Rehabil 2017;30(3):625-33.

8. Sano A, Hirano T, Watanabe K, Endo N, Ito T, Tanabe N Body mass index is associated with low back pain in childhood and adolescence: a birth cohort study with a 6-year follow-up in Niigata City, Japan. Eur Spine J. 2015;24(3):474-81.

9. Bailey JF, Shefi S, Soudack M, Kramer PA, Been E. Development of pelvic incidence and lumbar lordosis in children and adolescents. Anat Rec (Hoboken). 2019;302(12):2132-9.

10. Jankowicz-Szymańska A, Bibro M, Wodka K, Smola E. Does Excessive Body Weight Change the Shape of the Spine in Children? Child Obes. 2019;15(5):346-52.

11. Kasten AP, Rosa BND, Schmit EFD, Noll M, Candotti CT. Prevalência de desvios posturais na coluna em escolares: revisão sistemática com metanálisemeta-analysis. J Hum Growth Dev. 2017;27(1):99-108.

12. Orita, LL, Oliveira DV, Franco MF, Lima J. Estudos acerca da postura em crianças e adolescentes em fase escolar: relação com hábitos de vida. Cad Educ Fis Esporte. 2018;16(2):93-100. 
13. Conde WL, Monteiro CA. Body mass index cutoff points for evaluation of nutritional status in Brazilian children and adolescents. J Pediatr (Rio J). 2006;82(4):266-72.

14. Welk GJ, Maduro PFSM, Laurson KR, Brown DD. Field evaluation of the new FITNESSGRAM ${ }^{\circledR}$ criterion-referenced standards. Am J Prev Med. 2011;41(4 Suppl 2):S131-42.

15. Tanner J. Growth at adolescence. Oxford: Blackwell Scientific Publications; 1962.

16. Furlanetto TS, Candotti CT, Comerlato T, Loss JF. Validating a postural evaluation method developed using a Digital Image-based Postural Assessment (DIPA) software. Comput Methods Programs Biomed. 2012;108(1):203-12.

17. Takayama K, Kita T, Nakamura H, Kanematsu F, Yasunami $\mathrm{T}$, Sakanaka $\mathrm{H}$, et al. New predictive index for lumbar paraspinal muscle degeneration associated with aging. Spine. 2016;41(2): E84-90.

18. Kussuki M, João S, Cunha A. Caracterização Postural da Coluna de Crianças Obesas de 7 a 10 anos. Fisioter Mov. 2007;20(1):77-84.

19. Malepe MM, Goon DT, Anyanwu FC. The relationship between postural deviations and body mass index among university students. Biomed Res. 2015;26(3):437-42.

20. Smith AJ, O'Sullivan PB, Beales DJ, De Klerk N, Straker LM. Trajectories of childhood body mass index are associated with adolescent sagittal standing posture. Int J Pediatr Obes. 2011; 6(sup3):e97-106.

21. Silva LR, Rodacki ALF, Brandalize M, Lopes MFA, Bento PCB, Leite N. Alterações posturais em crianças e adolescents obesos e não-obesos. Rev Bras Cineantropom Desempenho Hum. 2011;13(6):448-54.

22. Rusek W, Baran J, Leszczak J, Adamczyk M, Weres A, Baran $\mathrm{R}$, et al. The Influence of Body Mass Composition on the Postural Characterization of School-Age Children and Adolescents. Biomed Res Int. 2018;9459014.

23. Mrozkowiak M, Walicka-Cupryś K, Magoń G. Comparison of Spinal Curvatures in the Sagittal Plane, as well as Body Height and Mass in Polish Children and Adolescents examined in the Late 1950s and in the Early 2000s. Med Sci Monit. 2018;24:4489-500.

24. Martins R, Andrade A, Moreira H, Almeida A. Prevalência e determinantes das perturbações músculo-esqueléticas em Adolescentes. J Clin Child Adolesc Psychol. 2016;7(1-2):73-82.
25. Cebeci AN, Taş A. Higher body fat and lower fat-free mass in girls with premature adrenarche. J Clin Res Pediatr Endocrinol. 2015;7(1):45-8.

26. Rogol AD, Roemmich JNCP. Growth at puberty. J Adolesc Health. 2002;31(6):192-200.

27. Nahas MV. Atividade física,saúde e qualidade de vida: conceitos e sugestões para um estilo de vida ativo. Londrina . 3 ed. Londrina: Midiograf; 2006.

28. Montoro APPN, Leite CR, Espíndola JA, Alexandre JM, da Reis MS, Capistrano R, et al. Aptidão física relacionada à saúde de escolares com idade de 7 a 10 anos. Abcs Heal Sci Cs. 2016;41(1):29-33.

29. Coupal KE, Heeney ND, Hockin BCD, Ronsley R, Armstrong K, Sanatani S, et al. Pubertal Hormonal Changes and the Autonomic Nervous System: Potential Role in Pediatric Orthostatic Intolerance. Front Neurosci. 2019;(13):1197.

30. Neinstein LS. Adolescent health care: a practical guide. Philadelphia: Lippincott Williams \& Wilkins; 2008.

31. WHO Scientific Group on the Burden of Musculoskeletal Conditions at the Start of the New Millennium. The burden of musculoskeletal conditions at the start of the new millennium. World Health Organ Tech Rep Ser. 2003;919:i-x,1-218.

32. Stodden DF, Goodway JD, Langendorfer SJ, Roberton MA, Rudisill ME, Garcia C, et al. A developmental perspective on the role of motor skill competence in physical activity: An emergent relationship. Quest. 2008;60:290-306.

33. Feng Q Jiang C, Zhou Y, Huang Y, Zhang M. Relationship between spinal morphology and function and adolescent non-specific back pain: a cross-sectional study. J Back Musculoskelet Rehabil. 2017;30(3): 625-33.

Received: $11 / 20 / 2019$

Recebido: 20/11/2019

Approved: 03/06/2020

Aprovado: 06/03/2020 